with England and Wales, where only 7000-8000 are notified to the Home Office yearly (though the actual number may be five to 10 times greater), is dangerous if we assume that experience of issuing its needles, syringes, and opiates to drug takers is relevant to us. Thirdly, Dr Moss seems unaware that intravenous drug misusers in this country have encountered few, if any, barriers in obtaining needles and syringes. In many areas of the country needles and syringes may be bought from chemists at a cost that is insignificant when compared with the expenses of drug misuse generally.

I would argue that there is a considerable risk that issuing free needles and syringes will increase this mode of self administration of drugs in the United Kingdom. If schemes are designed to restrict the issue of needles and syringes to established intravenous drug takers we would miss the most vulnerable intravenous misusers: those just starting to inject themselves. Though I share the concern of the government and many other agencies about HIV infection and the acquired immune deficiency syndrome, I would question the value of current proposed countermeasures and wonder whether we would be better to debate more pertinent issues, such as the compulsory treatment of the population at risk, as occurs elsewhere. ${ }^{1}$

Yorkshire Regional Drug Dependency Unit,

Peter J W WOOD

Waddiloves Hospital

Bradford BD8 7BT

1 Bucknell B. Some proposals for drugs legislation. Br $\mathcal{f}$ Addic 1985;80:149-52.

\section{Who may give blood?}

SIR,-Controversy surrounds the selection and testing of blood donors. We write to provide detail of our case, which was cited by Dr Marcela Contreras (17 January, p 176) and has been the subject of considerable speculation elsewhere.

The donor gave blood in April, August, and October 1986. The October donation was shown to contain antibody to human immunodeficiency virus (HIV) by competitive electroimmunoassay (Wellcozyme) (confirmable by Western blotting) An archive aliquot from the August donation was examined in the reference laboratory but contained no antibody to HIV as shown by competitive electroimmunoassay, Western blotting, or assay for specific antibody to the HIV envelope and core (Abbott Laboratories). A test has recently become available for p24 antigen, but a borderline result was obtained. Two patients had received the donation. One showed seroconversion to HIV and the other had antibody to HIV 14 weeks after transfusion, although he was not a member of a risk group. There seem to be only two published reports of transmission of HIV by blood definitely negative for antibody to HIV to recipients with no other risk factors, ${ }^{1}$ though other cases are apparently under investigation.

No evidence of either HIV antigen or antibody was found in the April donation by the same techniques. Both recipients subsequently died, but an archive specimen from the platelet recipient 52 days after transfusion was negative for antigen and antibody. Accordingly, we have no evidence that this donation was infective.

Subsequently, after an interview, the donor was assigned to a recognised risk group. This incident would not have been prevented by Dr Dawson's proposals to extend the risk groups. Before a test for HIV antigen may be regarded as a useful additional screen it will need much shorter incubation times and must give clearly positive results with infective blood like the August donation.

Marlink et al showed the usefulness of Western blot in early seroconversion, ${ }^{2}$ but even the Western blot yielded negative results for the infected donation. This finding must not be used to justify the use of insensitive screens for antibody to HIV as specimens from other patients have reacted weakly to electroimmunoassay during seroconversion.

R J CRAWFORD

Glasgow and West of Scotland

R MITCHELL

Blood Transfusion Service, Carluke,

Lanarkshire ML8 5ES

Glasgow Royal Infirmary

Glasgow G4 0SF

Ruchill Hospital,

Glasgow G20 9NB

1 Zuck TF. Greetings-with comments on lessons learned this past year from HIV antibody testing and from counselling blood donors. Transfusion 1986;26:493.

2 Marlink RG, Allan JS, McLane MF, Essex M, Anderson KC Groopman JE. Low sensitivity of ELISA testing in early HIV infection. N Engl f Med 1986;315:1549.

\title{
AIDS and life years lost: one district's
} challenge

SIR,-Health authorities are being told that combating the acquired immune deficiency syndrome (AIDS) should be made a priority. There fore resources are going to have to be diverted, particularly to the traditionally underfunded services of genitourinary medicine and health education. How big this transfer should be raises the question of how important AIDS is compared with other threats to health. We tried to answer this question objectively by calculating Lewisham and North Southwark's expectations of life years lost because of AIDS and other conditions over the next five years.

tion and of the disease's incubation period. ${ }^{4} \mathrm{We}$ used a combination of the first two methods.

McEvoy and Tillett's log-linear model may be used with confidence only to 1988 (H E Tillett, personal communication). American predictions to 1988 (Coolfant planning conference, 4-6 June 1986) may be used to predict figures for the United Kingdom from 1989 on the basis of a three year time lag and 1:4 population ratio. ${ }^{3}$ The proportion of cases in the United Kingdom attributable to our district was assumed to remain the same as up to 1985 , when our 10 cases represented about $2 \%$ of the national total. The death rate was taken as $28 \%$ during the year of presentation and $55 \%$ in the following year, ${ }^{1}$ with a further $6 \%$ and $3 \%$ in subsequent years, to approach the four year mortality of $92 \%$. $^{5}$

Life years lost for AIDS and seven other conditions were calculated, with a life expectancy of 70 years being assumed. Years lost equalled 70 minus the age of death if under 70 years. Deaths over 70 were disregarded. The number of deaths and age at death for conditions other than AIDS were taken from district figures for 1985. The average age at death from AIDS was assumed to remain at the present level of 37 years.

The table shows the seven leading causes of life

Seven leading causes of life years lost in Lewisham and North Southwark in 1985

\begin{tabular}{lrc} 
Condition (ICD No) & $\begin{array}{c}\text { No of } \\
\text { deaths }\end{array}$ & $\begin{array}{c}\text { Life years } \\
\text { lost (to } \\
\text { age 70) }\end{array}$ \\
\hline Ischaemic heart disease (410-11) & 948 & 2340 \\
Respiratory tract cancer (140-9, 161-2) & 314 & 1365 \\
Suicide (E950-9) & 39 & 915 \\
Road traffic accidents (E810-9) & 35 & 900 \\
Cerebrovascular disease (430-8) & 397 & 670 \\
Breast cancer (174) & 87 & 550 \\
Chronic obstructive airways disease & & \\
$\quad(490-2,494-6)$ & 220 & 545 \\
\hline
\end{tabular}

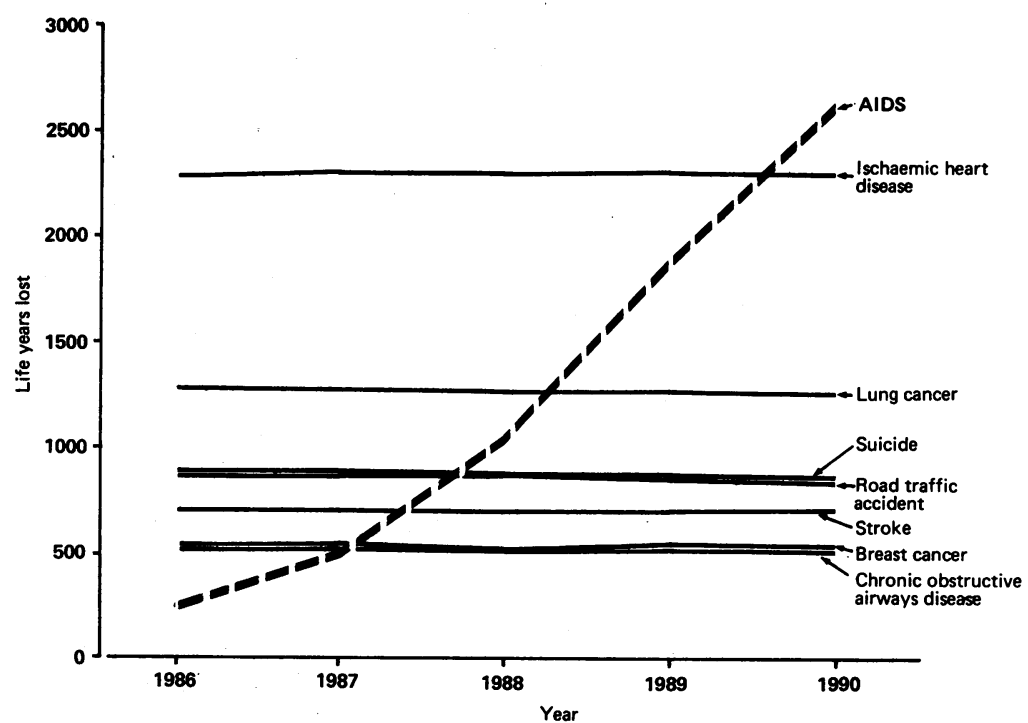

Leading causes of life years lost and AIDS in Lewisham and North Southwark 1986-90. The life years lost for AIDS are based on predicted numbers of deaths from AIDS in the.district of 7 in 1986, 15 in 1987, 32 in 1988, 57 in 1989, and 79 in 1990.

A combination of two methods was used: the fitting of epidemic predictions to AIDS cases nationally and locally and the calculation of life years lost for AIDS and other conditions. Nationally, three main methods of predicting the numbers of cases of AIDS have been described: the fitting of an epidemic curve,,$^{12}$ the application of the United States experience with a time lag, ${ }^{3}$ and the use of estimates of the existing infected popula- years lost in Lewisham and North Southwark in 1985 , and the figure summarises the calculations of life years lost owing to AIDS in the district, together with the seven other leading causes of life years lost. Until 1988 they are led by ischaemic heart disease and lung cancer. By 1988 AIDS ranks fourth, and by 1991 it will almost inevitably be the major health problem.

The current leading causes of premature death 